\title{
Sonographic evaluation of abdominal organs in sickle cell disease patients
}

\author{
Kaushal L', Verma VK², Ahirwar $\mathrm{CP}^{3}$, Patil $\mathrm{A}^{4}$, Singh $\mathrm{SP}^{5}$ \\ ${ }^{1}$ Dr Lovely Kaushal, Associate Professor \& Head, Department of Radiodiagnosis, GMC, Bhopal, ${ }^{2}$ Dr V K Verma, Associate \\ Professor, Department of Radiodiagnosis, GMC, Bhopal, ${ }^{3}$ Dr C.P.Ahirwar MD, Asst. Professor, Department of \\ Radiodiagnosis, GMC, Bhopal, ${ }^{4}$ Dr A Patil MD, Asst. Professor, Department of Radiodiagnosis, GMC, Bhopal, ${ }^{5}$ Dr Shakti \\ Pratap Singh, Resident, Department of Radiodiagnosis, GMC, Bhopal, MP, India
}

Address for correspondence: Dr Lovely Kaushal, Email: drlovelykaushal@gmail.com

\begin{abstract}
Background: SCD is one of the most common inherited hemoglobinopathies worldwide. It is a major health problem in Madhya Pradesh and surrounding states. The present study was undertaken to infer the value of ultrasonography in evaluating abdominal organs in a SCD patient. Study design: This is a prospective hospital based study. Method: 100 SCD patients were assessed for abdominal pathologies by USG, the results thus analyzed and prevalence was calculated. Result: Hepatomegaly is the most common association observed in $69 \%$ of patients followed by splenomegaly in $31 \%$ patients \& increased renal size in $29 \%$ patients. Cholelithiasis (17\%), increased renal medullary echogenecity (14\%), Auto-splenectomy (11\%), Bright liver (9\%), Splenic calcification (8\%), Increased GB wall thickness $(6 \%)$, Splenic infarct (5\%) and Increased pancreatic echogenicity (3\%) are the other associated findings. Conclusion: Real time ultrasonography is a simple, cheap, rapid, easily accessible, non-invasive, non-ionizing screening procedure in all cases of SCD patient for assessment of pathological changes occurring in the various abdominal organs. The high rates of abdominal pathologies being diagnosed on ultrasonography underscores the need for it to be established as a standard screening procedure with established protocols.
\end{abstract}

Key Words: Sickle cell disease (SCD), Ultrasonography, Hemoglobinopathies

\section{Introduction}

Sickle cell disease (SCD) is among the most common of inherited hemoglobinopathies. The disease has been known since James Herrick, a Chicago cardiologist, in 1910 first reported it as "peculiar elongated and sickleshaped red corpuscles in a case of severe anemia" [1].

The term sickle cell disease (SCD) is a group of inherited disorders characterized by defective hemoglobin $(\mathrm{Hb})$ synthesis.

A single mutation leads to replacement of Glutamic acid with Valine in position 6 of the $\beta$ globin chain resulting in a mutant form of $\mathrm{Hb}$ known as Sickle $\mathrm{Hb}(\mathrm{HbS})[2,3]$. In certain states like Madhya Pradesh, Orissa, Chhattisgarh, Jharkhand, Gujrat and Maharashtra it forms a major public health problem [4].

Sickle cell disease, particularly in homozygous state, has a significant contribution to the morbidity and mortality of this disorder during crisis. The various types of crisis cause changes in different organs of the body, some of which may have long term complications to the sickle cell

Manuscript received: $22^{\text {nd }}$ Jan 2014

Reviewed: $15^{\text {th }}$ Feb 2014

Author Corrected: 23 ${ }^{\text {rd }}$ Mar 2014

Accepted for Publication: 30 ${ }^{\text {th }}$ Mar 2014

International Journal of Medical Research and Review patient. Most of these changes occur in the abdominal organs, that is the liver, kidneys, spleen, gall bladder, as well as the pancreas. Early detection of these changes enables the caretakers to take preventive measures. Real time Ultrasonography is the most simple, cheap, easily accessible, non-invasive \& non-ionizing modality playing an important role in detecting early pathological changes so that appropriate interventional measures can be carried out.

Real time ultrasonography is now becoming standard screening procedure in all cases of SCD patients for assessment of pathological changes occurring in the abdominal organs, especially liver, biliary tract, spleen, kidneys and pancreas. The extent \& changes in the various organs can be accurately observed by US and there by helps the clinicians to modulate their treatment.

In all cases of acute SCD crisis, On the basis of Ultrasonographic findings they can be divided, whether they need surgical or medical intervention. This study is about the sonographic evaluation of abdominal organs in sickle cell disease. The Present study is a Prospective study conducted in GMC \& HH Bhopal, in Madhya Pradesh, India. We have conducted this study to determine the prevalence and distribution of abnormal

Available online at: $\underline{\text { www.ijmrr.in }} 202$ | P a g e 
Ultrasongraphic findings in the liver, biliary tracts, Spleen, kidneys And Pancreas of patients with SCD.

\section{Material \& Methods}

Study Design:- Prospective hospital based study.

Study Area:- Gandhi Medical College \& Hamidia Hospital Bhopal.

Sample Source:- SCD patients from all the departments of GMC \& HH referred to department of Radiodiagnosis for Ultrasonography of abdomen.

Sample Size:- 100 patients

Inclusion Criteria:- All the cases taken for study were sickling positive.

Exclusion criteria:- Negative sickling test, Positive operative history of splenectomy or others.

Technique of Scanning:- The Scan should be started with a convex probe of $3.5 \mathrm{MHz}$ used for visualization of solid organs, and linear array probe $7-10 \mathrm{MHz}$ used for visualization of bowel and superficial tissues.

\section{Definition of Terms}

Hepatomegaly: For adults patient's hepatomegaly was taken as length greater than $15.5 \mathrm{~cm}$ in long axis [5]. however other criteria for hepatomegaly are preaortic $>10 \mathrm{~cm}$ and prerenal $>14 \mathrm{~cm}$. The organ size was compared to the Indian reference population obtained from a study published on Indian population [6].

Bright liver: A normal liver is more echogenic than the renal cortex and less echogenic than the spleen [5].

Splenomegaly: For adult patients, splenomegaly was taken as length greater than $13.0 \mathrm{~cm}$ in long axis [5]. The organ sizes was compared to the Indian reference population obtained from a study published on Indian population [6].

Renal enlargement: Upper limits of normal right and left kidney were taken as $12.8 \mathrm{~mm} \& 13 \mathrm{~mm}$ respectively for adults [7].

Increased renal echogenicity: Normal renal echogenicity is typically less than adjacent liver and spleen [5].

Thickened GB wall: A thickened gall bladder wall measures $>3 \mathrm{~mm}$ and typically has a layered appearance on ultrasonography [8].

Increase pancreatic echogenicity: The normal pancreas has been stated to have echogenicity equal to or just greater than that on gray-scale images.

\section{Results}

Figure 1: Distribution of sample population by sex

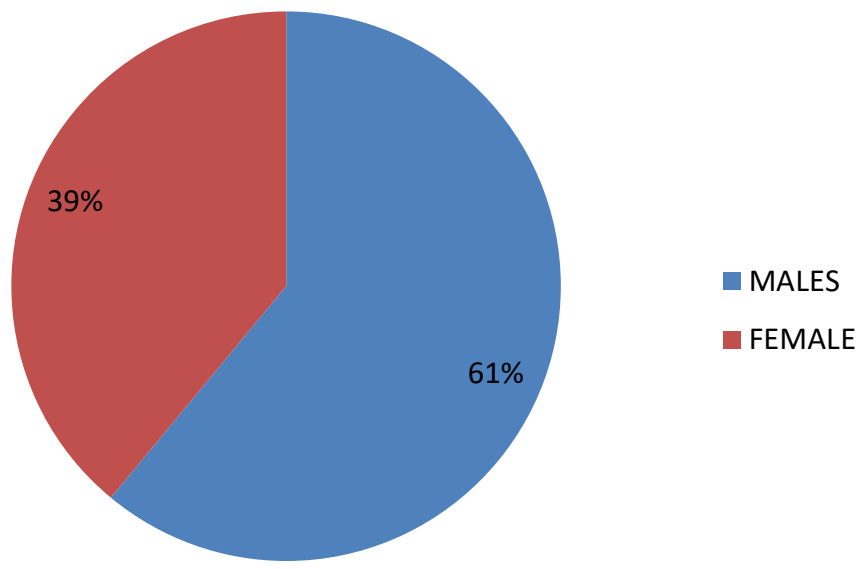

This study comprises of 100 patients out of which 61 (61\%) were males and $39(39 \%)$ were females. Males were more common in our study comprising $61 \%$ followed by $39 \%$ female. 
Figure 2: Distribution of patients in age groups

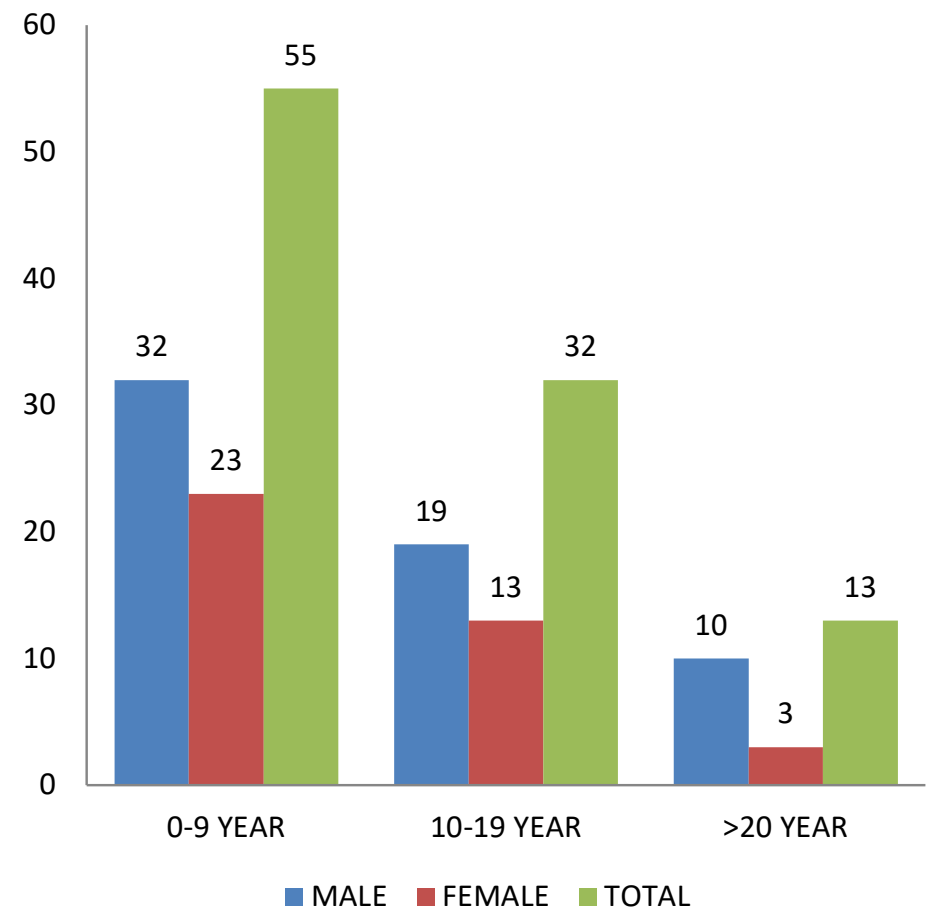

Showing subjects distribution in various age groups. The age groups $0-9$ years consisting of $55(55 \%)$ patients out of which $32(58.2 \%)$ are males and $23(41.8 \%)$ are females. 10- 19 years consisting of 32(32\%) patients out of which $19(59.4 \%)$ are males and $13(40.6 \%)$ are females. Least number of patients were of > 20year age group being 13 out of which 10 (76.9\%) are males and $3(23.1 \%)$ are females.

Table 1: Distributions of ultrasonographic findings in liver by age

\begin{tabular}{|c|c|c|c|c|}
\hline \multirow{2}{*}{ Ultrasonographic Findings } & \multicolumn{3}{|c|}{ Age Years } & \multirow{2}{*}{ Total } \\
\cline { 2 - 5 } & $\mathbf{0 - 9}$ & $\mathbf{1 0 - 1 9}$ & $\mathbf{2 0}+$ & 27 \\
\hline Normal Liver & $14(25.4 \%)$ & $10(31.25 \%)$ & $3(23.1 \%)$ & 69 \\
\hline Hepatomegaly & $43(78.1 \%)$ & $17(53.1 \%)$ & $9(69.2 \%)$ & 9 \\
\hline Bright Liver & $1(1.8 \%)$ & $6(18.8 \%)$ & $2(15.4 \%)$ & $\mathbf{1 0 0}$ \\
\hline Total & $\mathbf{5 5}(\mathbf{5 5} \%)$ & $\mathbf{3 2}(\mathbf{3 2} \%)$ & $\mathbf{1 3}(\mathbf{1 3} \%)$ & $\mathbf{1 0})$ \\
\hline
\end{tabular}

Hepatomegaly is found to be the most consistent finding with an overall prevalence of $69 \%$ and prevalence of $68.8 \%$ in males and $69.2 \%$ in females. It is most commonly seen in $0-9$ years $(78.1 \%)$ of age. The prevalence of bright liver is $11.5 \%$ in males and $5.1 \%$ in females with a much higher prevalence in age group of $10-19$ years $(18.8 \%)$.

Table 2: Distribution of Ultrasonographic Findings in Gall Bladder by Age

\begin{tabular}{|c|c|c|c|c|}
\hline \multirow{2}{*}{ Ultrasonographic Findings } & \multicolumn{3}{|c|}{ Age Years } & \multirow{2}{*}{ Total } \\
\cline { 2 - 5 } & $\mathbf{0 - 9}$ & $\mathbf{1 0 - 1 9}$ & $\mathbf{2 0}+$ & 83 \\
\hline Normal Gall Bladder & $50(90.9 \%)$ & $28(87.5 \%)$ & $5(38.5 \%)$ & 6 \\
\hline Increased Wall Thickness & $2(3.6 \%)$ & $1(3.1 \%)$ & $3(23.1 \%)$ & 17 \\
\hline Cholelithiasis & $7(12.7 \%)$ & $3(9.4 \%)$ & $7(53.8 \%)$ & $\mathbf{1 3}$ \\
\hline Total & $\mathbf{5 5}$ & $\mathbf{3 2}$ & $\mathbf{1 0 0}$ \\
\hline
\end{tabular}


An overall prevalence rate of $17 \%$ was noted in the cases of cholelithisis with prevalence of $16.4 \%$ in males and $17.9 \%$ in females. Prevalence of Increased Gall bladder wall thickness was noted as $6 \%$ and the prevalence being 3.3\% in males and $10.2 \%$ in females. The overall prevalence of increased Gall bladder wall thickness and cholelithiasis was found to increase with an increase in age and had a slight female preponderance.

Table 3: Distribution of Ultrasonographic Findings in Spleen by Age

\begin{tabular}{|c|c|c|c|c|}
\hline \multirow{2}{*}{ Ultrasonographic Findings } & \multicolumn{3}{|c|}{ Age Years } & \multirow{2}{*}{ Total } \\
\cline { 2 - 4 } & $\mathbf{0 - 9}$ & $\mathbf{1 0 - 1 9}$ & $\mathbf{2 0}+$ & 46 \\
\hline Normal Spleen & $34(73.9 \%)$ & $10(21.7 \%)$ & $2(4.3 \%)$ & 31 \\
\hline Splenomegaly & $19(34.5 \%)$ & $8(25 \%)$ & $4(30.8 \%)$ & 5 \\
\hline Splenic Infarct & $0(0 \%)$ & $4(12.5 \%)$ & $1(7.7 \%)$ & 8 \\
\hline Splenic Calcifications & $2(3.6 \%)$ & $6(18.8 \%)$ & $0(0 \%)$ & 11 \\
\hline Autosplenectomy & $0(0 \%)$ & $6(18.8 \%)$ & $5(38.5 \%)$ & $\mathbf{1 0 0}$ \\
\hline Total & $\mathbf{5 5 ( 5 5 \% )}$ & $\mathbf{3 2 ( 3 2 \% )}$ & $\mathbf{1 3}(\mathbf{1 3} \%)$ & $\mathbf{1 0})$ \\
\hline
\end{tabular}

Splenomegaly is the second most common finding with an overall prevalence of $31 \%$, the prevalence being $29.5 \%$ in males and $33.3 \%$ in females. It was observed that the prevalence of splenomegaly is higher in 0-9 year age group. The other significant finding in spleen is Auto-splenectomy with an overall prevalence of $11 \%$. An increase in prevalence of autosplenectomy with age is noticed in the study with a slight male preponderance. The overall prevalence of splenic infarct and splenic calcification is $5 \%$ and $8 \%$ respectively. However, the prevalence of splenic infarct and calcification was higher in the age group of 10-19 years. A slight female preponderance is noted in cases of splenomegaly and calcification.

Table 4 Distribution of Ultrasonographic Findings in Spleen by Sex

\begin{tabular}{|c|c|c|c|}
\hline \multirow{2}{*}{ Ultrasonographic Findings } & \multicolumn{2}{|c|}{ Sex } & \multirow{2}{*}{ Total } \\
\cline { 2 - 4 } & Male & Female & 46 \\
\hline Normal Spleen & $24(39.3 \%)$ & $22(56.4 \%)$ & 31 \\
\hline Splenomegaly & $18(29.5 \%)$ & $13(33.3 \%)$ & 5 \\
\hline Spenic Infarct & $3(4.9 \%)$ & $2(5.1 \%)$ & 8 \\
\hline Splenic Calcifications & $4(6.5 \%)$ & $4(10.2 \%)$ & 11 \\
\hline Autosplenectomy & $8(13.1 \%)$ & $3(7.7 \%)$ & $\mathbf{1 0 0}$ \\
\hline Total & $\mathbf{6 1 ( 6 1 \% )}$ & $\mathbf{3 9}(\mathbf{3 9 \%})$ & \\
\hline
\end{tabular}

The prevalence of splenomegaly \& splenic calcification is slightly higher in female; however the prevalence of splenic infarct has no sex preponderance. The prevalence of auto-splenectomy is slightly higher in male patients.

Table 5 Distribution of Ultrasonographic Findings in Kidneys by Age

\begin{tabular}{|c|c|c|c|c|}
\hline \multirow{2}{*}{ Ultrasonographic Findings } & \multicolumn{3}{|c|}{ Age Years } & \multirow{2}{*}{ Total } \\
\cline { 2 - 5 } & $\mathbf{0 - 9}$ & $\mathbf{1 0 - 1 9}$ & $\mathbf{2 0}+$ & 68 \\
\hline Normal Kidneys & $37(67.2 \%)$ & $23(71.8 \%)$ & $2(61.5 \%)$ & 29 \\
\hline Increase Size & $20(36.4 \%)$ & $7(21.9 \%)$ & $3(23.1 \%)$ & 14 \\
\hline Increased Medullary Echogenicity & $5(9.1 \%)$ & $6(18.7 \%)$ & $\mathbf{1 3}$ & $\mathbf{1 0 0}$ \\
\hline Total & $\mathbf{5 5}$ & $\mathbf{3 2}$ & & $\mathbf{1 0}$ \\
\hline
\end{tabular}

The 3rd most common finding noted in the study was increased renal size with an overall prevalence of $29 \%$ and the prevalence being $29.5 \%$ in males and $28.2 \%$ in females. It was observed that prevalence is higher in age group of $0-9$ years. The increased medullary echogenicity was noted in $14 \%$ of patients with a prevalence of $13.1 \%$ in males and $15.4 \%$ in female with a maximum prevalence in $>20$ years age group demarcating an increase in prevalence with age. However, the presence of confounding factors cannot be excluded. 
Table 6: Distribution of Ultrasonographic Findings in Pancreas by Age

\begin{tabular}{|c|c|c|c|c|}
\hline \multirow{2}{*}{ Ultrasonographic Findings } & \multicolumn{3}{|c|}{ Age Years } & \multirow{2}{*}{ TOTAL } \\
\cline { 2 - 4 } & $\mathbf{0 - 9}$ & $\mathbf{1 0 - 1 9}$ & $\mathbf{2 0 +}$ & \\
\hline Normal Pancreas & $53(96.4 \%)$ & $32(100 \%)$ & $12(92.3 \%)$ & 97 \\
\hline Increased Echogenicity & $2(3.6 \%)$ & $0(0 \%)$ & $1(7.7 \%)$ & 3 \\
\hline Total & $\mathbf{5 5}$ & $\mathbf{3 2}$ & $\mathbf{1 3}$ & $\mathbf{1 0 0}$ \\
\hline
\end{tabular}

Increased echogenicity of pancreas (viz a viz echogenic pancreas) is having a prevalence of 6\%. It was observed that the echogenicity of pancreas increases with age, however no sex preponderance was observed.

Cholodocholithiasis with dilated CBD was observed in 1 patient out of the study group of 100 patients. However, a significant correlation with disease in question could not be established. The finding may be considered as a rare complication.

\section{Discussion}

The Present study is a prospective study conducted in GMC \& HH Bhopal, from June 2012 to December 2013 in Madhya Pradesh, India for Ultrasonographic evaluation of abdominal organs in sickle cell disease done on SCD patients referred for ultrasonography from various Department of Gandhi Medical College \& Hamidia Hospital.

\section{Liver}

Vascular occlusion, viral hepatitis, iron overload, and drug reactions mainly contribute to SCD related Liver diseases. In our study Hepatomegaly is the most common pathological finding, its prevalence being 69\%. This concurs with the study done by Papadaki et al in 2003[9] cited before whereby the prevalence of hepatomegaly was $70.5 \%$.

This is also in accordance with the study done by Ali balci et al in 2004 [10], Mohanty et al [11] in 2004, whereby the prevalence of hepatomegaly was $71.6 \%$ \& $72 \%$ respectively. However this frequency is slightly lower compared to studies done by Bakhieta Ibrahim et al in 2010 [12] \& Sadishu et al [13] in 2012 whereby the prevalence of hepatomegaly was $87.8 \%$ \& $98.6 \%$ respectively, and much higher than the study done by Hamim et al in 2012 where it was 28.3\%.[14]

Several features of liver histology in patients with SCD may contribute to bright liver including hemosiderin pigment deposition, periportal fibrosis, and distension of sinusoids with sickle cells. In our study prevalence of Bright Liver (Increased liver echogenicity) was found to be $9 \%$. This concurs with the study given by Hamim et al in 2012 whereby the prevalence of bright liver was $12.5 \%$. However this frequency is slightly higher than the

International Journal of Medical Research and Review study did by Papadaki et al in 2003 [9] \& Ali Balci et al in 2004 [10] in which the prevalence of bright liver was $3.8 \%$ \& $5.9 \%$ respectively.

\section{Spleen}

The spleen possesses a slow, tortuous microcirculation that renders it quite susceptible to congestion, sludging, and polymerization culminating into pathologies like splenomegaly, splenic infarct, splenic calcification \& auto-splenectomy [15].

In our study, the prevalence of splenomegaly was found to be $31 \%$. This is slightly higher than the studies done by Ma'aji et al in 2012 [16] where the prevalence of splenomegaly was $22.4 \%$ \& $21.2 \%$ respectively. However the prevalence of splenomegaly in studies given by Ahmed H et al in 1997 [17] \& Babadoko et al in 2011 [18] was $11.8 \%$ \& $4.05 \%$ respectively.

The repeated sickling of red cells in the splenic circulation over time leads to splenic infarction. In our study the prevalence of splenic infarct was found to be $5 \%$. It concurs with the study given by Hamim A et al in 2010 [14] where the prevalence of splenic infarct was observed as $6.6 \%$. However, this is quite below the study given by Mohanty et al in 2004 [14] where the prevalence of splenic infarct was found to be $22 \%$.

In our study the prevalence of splenic calcification is $8 \%$. This concurs with the study given by Mohanty et al in $2004{ }^{[11]}$ where the prevalence of splenic calcification was found to be $10 \%$.

In our study the prevalence of autosplenectomy is observed as $11 \%$. This frequency is slightly higher than 
the study done by Ahmed H Salem et al in 1997 [17], Hamim A et al in 2010 [14] \& Ma'aji et al in 2012 [16] where the prevalence of autosplenectomy was observed as $6.6 \%, 6.6 \%$ \& $4.2 \%$ respectively. However, the prevalence of auto-splenectomy was much higher in study given by Ali Balci et al in 2004 [10], Bakhieta et al in 2010 [12] \& Babadoko et al in 2011 [18] whereby the prevalence of auto-splenectomy was $33.3 \%, 47.8 \%$ \& $55.4 \%$ respectively.

\section{Gall bladder}

Gallstones are a common complication in patients with SCD owing to stasis, chronic hemolysis and repeated blood transfusions [14]. In our study the prevalence of Gall Stones was observed as $17 \%$. This is in accordance with the studies given by Mohanty et al in 2004 [11] \& Hamim et al [14] in 2010 where the frequency of gall stones were found to be $22 \%$ \& $17 \%$ respectively.

However higher frequency of gall stones were found in studies given by Ali Balci et al in $2004{ }^{[10]}$ as $30.4 \%$. A lower frequency of gall stone was observed in studies given by Bakhieta et al in 2010 [12] as $11.1 \%$. A thickened gall bladder wall measures $>3 \mathrm{~mm}$ and typically has a layered appearance on ultrasonography. In our study Thickened GB wall have a prevalence of $6 \%$. This is in accordance with the study given by DA Nzeh et al in 1989 [19], whereby the prevalence of thickened GB wall was $8.1 \%$. In another study by Bakhieta et al in 2010 [12], the frequency of thickened GB wall was $2.2 \%$.

\section{Kidney}

Renal enlargement is a common finding in patients with sickle cell disease as a result of glomerular hypertrophy \& increased renal blood volume [16]. In our study the prevalence of renal enlargement was observed to be $29 \%$ which is in accordance with the study of Ali Balci et al in 2004 [10] where the prevalence of renal enlargement was given as $30.4 \%$. Increase in renal echogenicity can be attributed to factors like renal papillary necrosis, high concentrations of iron deposits within the tubular epithelial cells, focal scarring \& interstitial fibrosis in vasa recta system, glomerular hypertrophy and renal sclerosis $[20,21]$. In our study the prevalence of increased renal medullary echogenicity was observed as $14 \%$.

This concurs with the study of Ali Balci et al in 2004 [10], Mohanty et al in 2004 [11] \& Namjosh et al [22], whereby the prevalence of increased renal medullary echogenicity was $15.7 \%, 16 \% \& 13.8 \%$ respectively. A slightly higher frequency of increased renal echogenicity was seen in studies given by Walker et al in 1995 [18],
Papadaki et al in 2003 [9] \& Ibinaiye et al in 2013 [18] as $20 \%, 17.6 \% \& 18.9 \%$ respectively.

\section{Pancreas}

Iron deposition in the pancreas or pancreatic hemosiderosis causes the pancreas to be echogenic on US. In our study, increased echogenicity of pancreas was observed as $3 \%$. This concurs with the study done by Ali Balci et al in 2004 [10] in which echogenic pancreas was found in $3.9 \%$ patients.

\section{Conclusion}

Real time Ultrasonography should be established as a routine screening procedure in sickle cell disease patients and thereafter as a routine follow up measure. The early detection of pathological changes and immediate intervention measures reduces the morbidity and mortality, thereby increasing the life expectancy. More studies should be conducted to establish initial age limit for screening and for intervals of routine follow-up with respect to both homozygous and heterozygous karyotypes.

\section{Funding: Nil}

\section{Conflict of interest: Nil}

Permission from IRB: Yes

\section{References}

1. Herrick JB. Peculiar elongated and sickle-shaped red blood corpuscles in a case of severe anemia. Arch Int Med $1910 ; 6: 517-520$

2. Bunn HF. Induction of fetal hemoglobin in sickle cell disease. Blood 1999; 93:1787-1789.

3. Rodgers GP. Overview of pathophysiology andrationale for treatment of sickle cell anemia. SeminHematol 1997; 34:2-7.

4.H. Lehman and M. Cutbush, "Sickle Cell Trait in Southern India," British Medical Journal, Vol. 1, No.4755, 1952, pp. 404-405

5. Dick R, Watkinson A. The liver and spleen. In: Sutton $\mathrm{D}$, ed. Textbook of radiology and imaging. $7^{\text {th }}$ ed New York: Elsevier, 2002; 737-786.

6. Bhavna Dhingra, Suvasini Sharma, Devendra Mishra. 2009. Normal values of Liver and Spleen Size by Ultrasonography in Indian Children. PN:S097475590800697-1. 
7. Miletic D, Fuckar Z, Sustic A, Mozetic V, Stimac D, Zauhar G. sonographic measurements of absolute and relative length in adults. JClinUltrasound1998;26:185-189

8. Rumack CM, Wilson SR, Charboneau JW. Diagnostic ultrasound, $2^{\text {nd }}$ ed. St. Louis, MO: Mosby, 1998:175-200

9. Papadaki MG, Kattamis AC, Papadaki IG, Menegas DG, Georgakopoulou TP, Mavrommati-Metaxotou A, et al. Abdominal ultrasonographic findings in patients with Sickle cell anemia and thalassemia intermedia. PediatrRadiol 2003;33:515-21

10. Balci A, Karazincir S, Sangün O, Gali E, Daplan T, Cingiz C. Prevalence of abdominal ultrasonographic abnormalities in patients with sickle cell disease. DiagnIntervRadiol 2008;14:133-7

11. Mohanty J, Narayan J, Bhagat S, Panda BB, Satpathi $\mathrm{G}$, Saha N. sonologicalevealuation of abdominal organs in sickle cell crisis in Western Orissa. Indian Journal of Radiology and Imaging 2004; 14:247-51

12. Bakhieta IT. Sonographic findings in Sudanese children with sickle cell anaemia. J Diagn Med Sonography 2010;6:281-5

13. Ma'aji SM, Jiya NM, Saidu SA, Danfulani M, Yunusa GH, Sani UM, Jibril B, Musa A, Gele HI, Baba MS, Bello S. Transabdominalultrasonographic findings in children with sickle cell anemia in Sokoto, North-Western Nigeria. Niger J Basic ClinSci [serial online] 2012 [cited 2013 Dec 17];9:14-7.

14. Hamim Abdul Rusheke. Abdominal ultrasonographic abnormalities in patients with sickle cell anaemia at muhimbili national hospital 2010; Muhimbili University of Health and Allied Science. ir.muhas.ac.tz:8080/jspui. http://hdl.handle.net/123456789/1046

15. Lane PA. Sickle cell disease. PediatrClin North Am 1996; 43:639-664

16. Ma'aji SM, Jiya NM, Saidu SA, Danfulani M, Yunusa GH, Sani UM, Jibril B, Musa A, Gele HI, Baba MS, Bello $\mathrm{S}$. Transabdominalultrasonographic findings in children with sickle cell anemia in Sokoto, North-Western Nigeria. Niger J Basic ClinSci [serial online] 2012 [cited 2013 Dec 17];9:14-7

17. Ahmed H.Salem et al: "Sonographic assessment of splenic size in Saudi patients with Sickle cell disease" Ann Saudi Med 1998;18(3):217-220.

18. Ibinaiye PO, Babadoko AA, Yusuf R, Hassan AA. Renal complications of sickle cell anemia in Zaria, Nigeria: An ultrasonographic assessment. West Afr J Radiol 2013;20:19-22

19. D.A. Nzeh\& M.A. Adedoyin et al. sonographic pattern of gall bladder disease in children with sickle cell disease. PediatrRadiol (1989) 19:290-292.

20. Namjoshi SP. Punctate echogenic foci in spleen and increase echogenicity in renal cortex in sickle cell Ameamia. J Clin Ultrasound 1999;27:52

21. Walker TM, Searjeant GR. Increased renal reflectivityin sickle cell disease: prevalence and characteristics. ClinRadiol 1995; 195:566-569.

22. Namjoshi SP. Punctate echogenic foci in spleen and increase echogenicity in renal cortex in sickle cell Ameamia. J Clin Ultrasound 1999;27:52.

\section{How to cite this article?}

Kaushal L, Verma VK, Ahirwar CP, Patil A, Singh SP. Sonographic evaluation of abdominal organs in a sickle cell disease patient. Int J Med Res Rev 2014;2(3):202-208. doi:10.17511/ijmrr.2014.i03.09 